\title{
PEMBUATAN ALAT PENGASAPAN IKAN DENGAN SISTEM ROTARY BERBAHAN BAKAR TEMPURUNG KELAPA
}

\author{
Jantri Sirait \\ Balai Riset dan Standardisasi Industri Samarinda
}

\begin{abstract}
ABSTRACK
A smoked fish equipment with rotary system using coconut shell fuel has been made. The cquipment is specified by $200 \mathrm{~cm}$ height and $100 \mathrm{~cm}$ in diameter of drying room, there levels of fish hanger and threc hangers of each level. Each hanger can hang $5-6 \mathrm{~kg}$ of fresh fish. These hangers can rotate powered by 1250 $1 \mathrm{pm}$ and 125 watt of electric motor. A gear box is installed to reduce the rotation speed of this motor. The amount of coconut shell that is needed for 18 hours driying of $45 \mathrm{~kg}$ finish product of smoked fish is $20 \mathrm{~kg}$.

The results of laboratory analysis of the smoked fish treted cat fish (Hemibagrus nemurus) and pandanus fish (Cryptopterus, Spp) meet with SNI O1 - 2725 - 1992 dried fish, except moid parameter. The parometer tested in this analyses are moisture contant, ash contant, salt contant. Total Plate Count (TPC). E-coli, salmonella Sp, and the moisture contant of the smoked fish produced is higher than its stondard of SNI.

Key word: smoked fish, coconut shell, rotary system
\end{abstract}

\section{PENDAHULUAN}

Kalimantan Timur mempunyai wilayah pesisir dan lautan yang sangat luas, memiliki potensi sumber daya perairan dan hayati yang dapat dikembangkan. Jumlah produksi ikan tangkapan di Kalimantan Timur dari tahun ke tahun mengalami peningkatan. Produksi ikan tangkap dan budidaya keramba di Kalimantan Timur tahun 2006 sebesar 4.75 juta ton meningkat sebesar 5,04 juta ton pada tahun 2007 (Dinas Kelautan dan Perikanan 2007). Pengasapan ikan sampai saat ini masih belum mendapatkan perhatian yang cukup dari industri perikanan, padahal pengembangan produk ikan asap mempunyai prospek di masa mendatang. Mengingat bahwa beberapa negara maju tingkat konsumsi produk ikan asap cukup bagus, maka upaya meningkatkan produksi dan kualitas bagi ikan asap di Indonesia perlu dilakukan.

Ikan merupakan bahan pangan yang mudah rusak (membusuk), hanya dalam waktu sekitar delapan jam scjak ikan ditangkap dan didaratkan akan timbul proses perubahan yang mengarah pada kerusakan. Oleh karena itu agar ikan dan hasil perikanan dapat dimanfaatkan semaksimal mungkin, perlu dijaga kondisinya. Pengolahan merupakan salah satu cara untuk mempertahankan ikan dari proses pembusukan. sehingga mampu disimpan lama sampai tiba waktunya untuk dijadikan bahan konsumsi. Usaha dalam melaksanakan pengolahan dapat dilakukan dengan berbagai macam cara yaitu ikan yang baru ditangkap dapat dipertahankan kesegarannya dengan cara didinginkan atau dibekukan, dan diolah menjadi ikan asap.

Pengasapan dapat dilakukan dengan dua cara, yaitu pengasapan dingin dan pengasapan panas, pengasapan dingin (cold smoking) adalah proses pengasapan dengan cara meletakkan ikan yang akan diasap agak jauh dari sumber asap (tempat pembakaran kayu), dengan suhu sckitar $45-50^{\circ} \mathrm{C}$ dengan lama proses pengasapan beberapa hari sampai dua minggu. Untuk Pengasapan panas ( hot smoking) adalah proses pengasapan ikan dimana akan diasapi cukup dekat dengan sumber asap. Suhu sekitar $70100^{\circ} \mathrm{C}$. lamanya pengasapan $2-4$ jam. htt.p://bisnisukm,com.Pembuatan Ikan Asap [diakses pada tanggal 19 Nopember 2009]. Pengasapan ikan yang dilakukan oleh para pengerajin saat ini masih bersifat tradisional yaitu dengan meletakkan ikan dekat dengan bara (hotsmoking) dengan menggunakan sumber panas arang kayu. Pengasapan dengan cara tradisional ini mempengaruhi terhadap mutu ikan asap bila ditinjau dari segi higenis dan lama simpan ikan asap, serta jumlah produksi yang sangat kecil. Pemanfaatan total produksi perikanan olch masyarakat sebagian besar dikonsumsi dalam bentuk ikan segar $43,1 \%$. beku $30.4 \%$, pengalengan $13,7 \%$, dan dalam bentuk olahan lain 12,8\%, (Wibowo, 1996). Pemanfaatan dalam bentuk olahan lain ini dapat 
berupa ikan asin, ikan asap, ikan pindang, produk fermentasi (petis,terasi,peda,dII).

Berdasarkan uraian diatas maka peneliti tertarik merancang alat teknologi tepat guna untuk pengasapan ikan dengan sistim rotary berbahan bakar tempurung kelapa. Diharapkan dengan terciptanya alat pengasapan ikan dengan sistem rotary berbahan bakar tempurung kelapa ini, mampu mengatasi kendala yang dihadapi para pembuat ikan asap, yaitu mampu meningkatkan jumlah produksi ,lebih higenis, dan meningkatkan lama simpan ikan asap.

\section{BAHAN DAN METODE}

Pengumpulan data dilakukan dengan cara survey dan wawancara langsung dengan para nelayan dilokasi pesisir pantai dan sungai, khususnya di Kalimantan Timur seperti muara Badak, Kota Bangun, Muara Muntai dan beberapa Kota lainya. Untuk mengetahui kendala-kendala yang dialami para pembuat ikan asap. Hal ini dilakukan sebelum pembuatan alat pengering.

Desain alat pengasapan ini dibuat dengan harga yang terjuangkau oleh para pengerajin ikan asap, sehingga dapat meningkatkan pendapatan para pengerajin ikan asap. Bahan yang digunakan untuk pembuatan alat pengasapan ini antara lain: plat, besi u, as, pipa, besi siku, bering, plat strip, engsel, ring, pully, belt, motor listrik, stereofoam, blower, Pisau stainless, Sarung tangan, cat. Sedangkan alat yang digunakan dalam penelitian ini antara lain; siku, mesin las, gergaji besi, meteran, kuas, kaca mata las. Ikan yang di asap dengan menggunakan alat pengasapan sistem rotary ini adalah ikan baung (Hemibagrus nemurus), dan ikan lais (Cryptopterus, Spp). dengan menggunakan bahan bakar tempurung kelapa.

Prosedur pengoperasian alat pengasapan dengan sistem rotari ini adalah; api didalam tungku pemanas dinyalakan dengan menggunakan bahan bakar tempurung kelapa sampai membara, kemudian ikan yang mau diasap digantung di dalam ruang pengasapan. Pada saat proses pengasapan ventilasi tungku jangan dibuka terlalu lebar karena bara didalam tungku mudah menyala. Agar pengasapan didalam ruang pengasapan merata terhadap ikan yang diasap hidupkan rotari pengasapan. Amati suhu ruang pengasapan antara $45 \quad 50^{\circ} \mathrm{C}$ jika ruang pengasapan diatas $50^{\circ} \mathrm{C}$ buka ventilasi cerobong.

Panas yang dibutuhkan guna mengeringkan ikan asap adalah $4550^{\circ} \mathrm{C}$, dimana jika ikan yang diasap dibawah suhu $45^{\circ} \mathrm{C}$ ikan akan mengerut dan jika ikan yang diasap diatas $50^{\circ} \mathrm{C}$ akan mengakibatkan pengerasan bagian luar ikan yang diasap (Kreith.F,1991). Dan untuk asap yang dibutuhkan pada saat proses pengasapan harus tebal agar aroma asap meresap pada ikan yang diasap pada saat kondisi ikan masih basah.

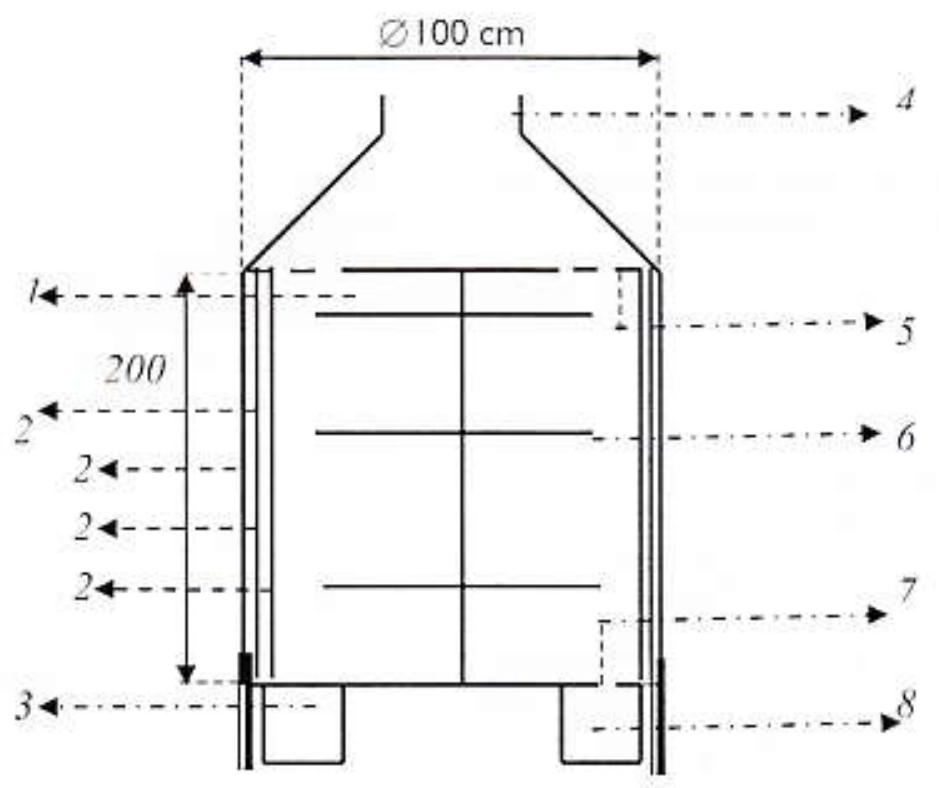

Gambar 1. Rangkaian Alac Pengasapan lkan. 
Keterangan gambar : 1 ruang pengasapan, 2.dinding pengasapan, 2a.lapisan dinding luar, $2 \mathrm{~b}$.lapisan dinding bagian dalam, $2 c$. Lapisan dinding paling dalam, 3.gear box, 4.cerobong udara, 5.pentilasi udara keluar, 6.gantungan ikan yang diasp. 7.pentilasi uap panas masuk, 8.tungku pemanas.

Alat pengasapan terdiri dari 5 komponen utama yaitu 1) ruang pengasapan, 2) gantungan ikan, 3) motor penggerak, 4) cerobong, 5) tungku pemanas. Prinsip kerja alat pengasapan ikan yang mekanis adalah memanaskan dengan menggunkan udara dan asap panas yang dialirkan dari tungku pemanas melalui ventilasi tungku pemanas, sebagai mana terdapat pada Gambar I.

\section{Ruang Pengasapan}

Ruang pengasapan (1) berfungsi untuk menampung asap dan udara panas yang masuk dari tungku pemanas (8) melalui ventilasi tungku (7), dan sebelum asap dan udara panas di buang keluar melalui cerobong (4) melalui ventilasi cerobong (5). Ukuran ruang pengasapan dibuat dengan ukuran diameter $100 \mathrm{~cm}$, dengan tinggi $200 \mathrm{~cm}$. Ruang pengering terdiri dari tiga lapis (2). tujuan dari lapisan ini ialah untuk menjaga agar ruang pengasapan tetap panas, dan panas yang di dalam ruang pengasapan tidak menyebar keluar. Lapisan dinding alat pengering terdiri dari ; dinding bagian luar terbuat dari besi plat dengan ukuran $2.5 \mathrm{~mm}(2 \mathrm{a})$, dinding bagian dalamnya dilapisi dengan glass wool ( $2 \mathrm{~b}$ ) untuk menjaga agar panas tidak terserap keluar, dan dinding paling dalam dilapisi dengan alumunium (2c). Fungsi dari penggunaan alumunium untuk menjaga agar bagian dalam alat pengasapan tidak korosif.(Balai Riset dan Standardisasi Industri Samarinda, 2006).

\section{Gantungan lkan}

Proses pengasapan ikan dilakukan dengan cara di gantung, hal ini di lakukan untuk menghindari kerusakan pada permukaan ikan (6). Kapasitas gantungan ikan sebanyak $50 \mathrm{~kg}$ terdiri dari tiga tingkat, dimana setiap tingkatnya di bagi menjadi tiga bagian dan masing masing gantungan mampu menampung ikan sebanyak 5 $6 \mathrm{~kg}$. Sclama proses pengasapan berlangsung. gantungan ikan akan berputar mengitari lobang masuk uap panas. Tujuan dari putaran gantungan ikan ini agar panas yang dari tungku merata ke seluruh ikan yang diasap, dan asap yang masuk kedalam ruang pengasapan merata ke seluruh ikan yang diasap, sebagai mana pada gambar 2.

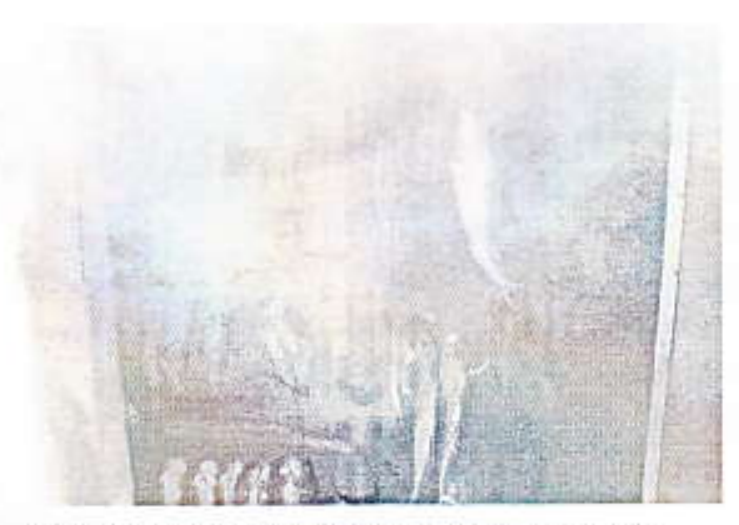

Gambar 2. Ruang pengasapan dan gantungan ikan

\section{Motor Penggerak}

Rancangan pengasapan ikan ini di buat dengan sistim mekanis dengan menggunakan motor penggerak (3), sehingga pada saat proses pengasapan kan berputar menyebabkan kedua sisi ikan yang diasap akan merata terkena panas dan asap panas pada saat melintasi ventilasi tungku pemanas.
Untuk memutar gantungan ikan dipakai motor listrik dengan daya 125 watt dan putaran $1250 \mathrm{rpm}$, dan untuk memperlambat putaran dipergunakan gear box. guna menghindari ikan yang digantung tidak jatuh pada saat pengasapan. 


\section{Cerobong}

Untuk membuang uap air yang timbul karena pemanasan terhadap ikan yang diasap. maka dirancang cerobong pembuangan diatas alat pengasapan (4). Cerobong ini dirancang tanpa menggunakan kipas atau blower. Untuk mempercepat laju keluar uap panas dan asap panas keluar dari ruang pengasapan dibuat tiga buah lubang pembuangan di dalam ruang pengasapan, sehingga dengan adanya tekanan panas dari tungku pemanas membuat uap panas dan asap panas yang akan keluar terdorong lewat ketiga lubang buangan dari dalam ruang pengasapan, seperti pada Gambar 3.

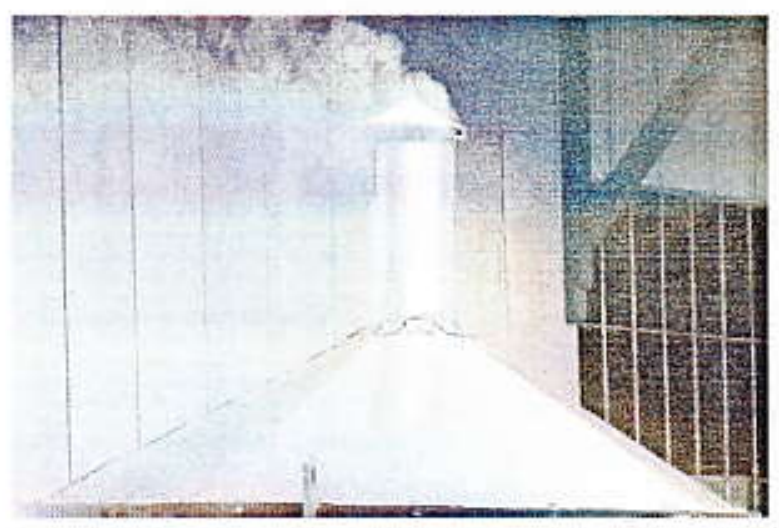

Gambar 3. Cerobong pengasapan ikan

\section{Tungku Pemanas}

Sumber bahan bakar yang dipergunakan dalam proses pengasapan ikan adalah tempurung kelapa. Pemilihan tempurung kelapa dilakukan karena tempurung kelapa mempunyai panas yang lebih lama dan mempunyai asap panas yang tebal. Tempurung kelapa pada saat dibakar tidak akan menjadi debu, melainkan jadi arang.
Tungku pemanas didesain dibawah alat pengasapan seperti pada gambar 4. Hal ini dilakukan guna menghindari penggunaan kipas atau blower. Ventilasi uap panas kedalam ruang pengasapan dirancang di bawah rak pengasapan ikan.

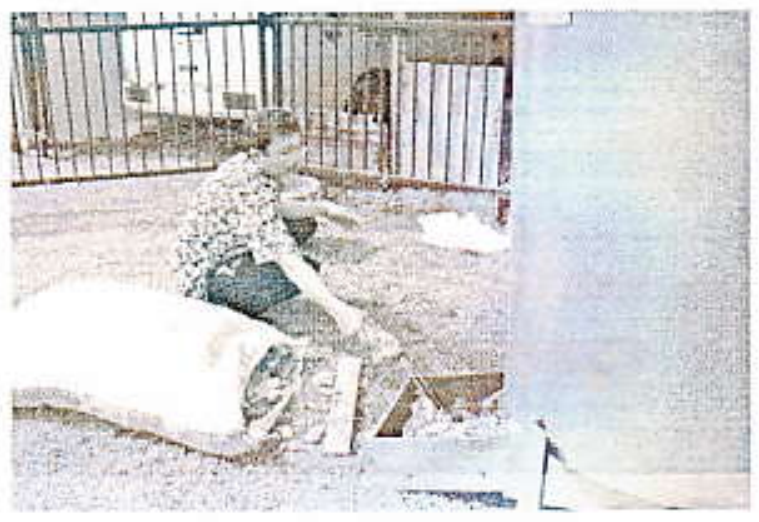

Gambar 4. Tungku pengasapan

\section{HASIL DAN PEMBAHASAN}

Rancangan alat pengasapan ikan terdiri dari; tinggi ruang pengasapan $200 \mathrm{~cm}$, diameter alat pengasapan $100 \mathrm{~cm}$, jumlah gantungan alat pengasapan terdiri dari tiga tingkat dan masing masing tingkat terdapat tiga gantungan dan masing masing gantungan dapat di gantung 5-6 $\mathrm{kg}$ ikan segar untuk diasap. Untuk memutar rotary pengasapan digunakan motor listrik dengan kapasitas 125 watt, dengan putaran 1250 rpm, dan untuk memperlambat putaran motor listrik terhadap rotary pengasapan dipergunakan gear box.

Untuk mengetahui uji unjuk kerja alat maka dilakukan evaluasi terhadap alat pengasapan yaitu lama pengasapan, suhu ruangan, kebutuhan bahan bakar, dan berat ikan yang diasap. dapat dilihat pada Tabel I.

Tabel I : Evaluasi Uji Unjuk Kerja Alat

\begin{tabular}{ll}
\multicolumn{1}{c}{ Parameter Evaluasi } & \multicolumn{1}{c}{ Satuan Kerja } \\
\hline Jumlah Pemakaian Bahan Bakar & $25 \mathrm{~kg} / 18 \mathrm{jam}$ \\
\hline Lama Pengasapan & $18 \mathrm{jam} / \mathrm{I} \mathrm{kali} \mathrm{proses}$ \\
\hline Berat Ikan yang diasap & $45 \mathrm{~kg} / \mathrm{I} \mathrm{kali} \mathrm{prose}$ \\
\hline Suhu Ruang Pengasapan & $45-50^{\circ} \mathrm{C}$ \\
\hline
\end{tabular}

Dari hasil uji unjuk kerja alat dilakukan pengujian terhadap ikan asap yang dihasilkan dengan parameter kadar air, kadar abu, TPC, Ecoli, Salmonella, Staphylococcus, kapang. 
Pada percobaan ini ikan yang diasap adalah ikan baung (Hemibogrus nemurus) dan ikan lais (Cryptopterus, Spp), dan sebagai pembanding di lakukan pengujian dengan parameter yang sama terhadap ikan asap yang dijual di pasar.
Dari hasil percobaan dengan menggunakan alat pengasapan tersebut kadar air ikan baung dan ikan lais memenuhi standard SNI 01-2725-1992. (Badan Standardisasi Nasional, SNI lkan Asap. 1992). sedangkan ikan pembanding yang dibeli dipasar memiliki kadar air yang tinggi. Hal ini dapat dilihat pada Tabel 2.

Tabel 2 : Kualitas Ikan asap

\begin{tabular}{lcccc}
\hline \multicolumn{1}{c}{ Parameter } & \multicolumn{2}{c}{ Jenis Ikan yang diasap } & Ikan Pare & SNI \\
\cline { 2 - 4 } & $\begin{array}{c}\text { Ikan } \\
\text { Baung }\end{array}$ & Ikan Lais & 1-2725 -1992 \\
\hline Kadar Air (\%) & 12,41 & 12,41 & 79,07 & Maks, 60 \\
\hline Kadar Abu (\%) & 1,376 & 1,376 & 1,20 & Maks, 1,5 \\
\hline Kadar Garam (\%) & 0,198 & 0,198 & 0,14 & Maks, 4 \\
\hline TPC (Kol/gram) & $3,0 \times 10^{3}$ & $3,0 \times 10^{3}$ & $3,4 \times 10^{8}$ & Maks, $5 \times 10^{5}$ \\
\hline Kapang (Kol/gram) & $3,0 \times 10^{3}$ & $3,0 \times 10^{3}$ & Negatif & Negatif \\
\hline E-coli (APM/gram) & $<3$ & $<3$ & 93 & 0 \\
\hline Staphylococcus & Negatif & Negatif & Negatif & Negatif \\
\hline Salmonella & Negatif & Negatif & Negatif & Negatif \\
\hline
\end{tabular}

Keterangan: Ikan Baung dan lkan Lais adalah ikan yang diasap dengan menggunakan alat yang direkayasa. Ikan pare adalah ikan asap yang di beli di pasar.

Asumsi yang dipakai dalam perhitungan teknik ekonomi alat pengasapan ini adalah : lama mesin berproduksi 24 jam/ hari, 20 hari kerja / bulan, 300 hari kerja / tahun. Kebutuhan listrik 3 $\mathrm{kwh} /$ hari, $75 \mathrm{kwh} / \mathrm{bulan}$ atau $900 \mathrm{kwh} / \mathrm{tahun}$. Sedangkan modal tetap senilai Rp.101.500.000,untuk harta tak bergerak seperti ; perijinan. sebidang tanah, satu unit bangunan, perlengkapan perkantoran seperti komputer, lemari, meja dan kursi, dan peralatan mesin. Untuk kebutuhan investasi atau modal kerja selama 3 bulan adalah Rp. 260.246.050.- dengan asumsi pinjaman dari BANK $50 \%$ dari investasi atau modal kerja.
Biaya administrasi dan umum dengan harga $R p$. $5.443 .000,-$, dan biaya pemasaran dengan harga Rp53.120,- atau I \% dari biaya penjualan. Dan untuk penjualan ikan asap diasumsikan $80 \mathrm{~kg} \times 20$ hr $\times 80 \% \times$ Rp. $50.000,-$, sehingga jumlah penjualan Rp.64.000.000,-. Kemudian bahan baku dan penolong diasumsikan Rp 40.040.000,Sedangkan untuk upah tenaga langsung untuk 2 orang di asumsikan Rp. 800.000,-- Dan untuk biaya over head pabrik di asumsukan Rp.6.579.230,-- Berdasarkan asumsi tersebut maka didapat hasil tekno ekonomi alat pengasapan ikan seperti pada Tabel 3. 
Tabel 3 : Tckno Ekonomi Alat Pengasapan lkan

\section{Uraian}

Hasil Produksi 1 tahun

Biaya Produksi 1 tahun

Biaya Variabel 1 tahun

Biaya Tetap 1 Tahun

Penjualan 1 tahun

BREAK EVEN POINT

$\operatorname{BEP}(\%)=$ Biaya Tetap

Penjualan - B. Variabel

BEPRp. = Biaya Tetap
1- Biaya variabel/ Penjualan

$\operatorname{BEP}(Q)=\underline{F C}$

Penj (Produk) - B. Variabe

(Produk)

\section{Perhitungan Balik Modal}
ROI $=$ Laba + Penyusutan $\times 100 \%$ TBP Jumlah Investasi

Waktu balik Modal $=1 / \mathrm{ROI}$

\section{Perhitungan}

19200

Rp. $634,984,200$

Rp. $564,240,000$

Rp. $70,744,200$

Rp. $768,000,000$

$70,744,200$

$768,000,000-564,240,000$

$\frac{\frac{70,744,200}{1-564,240,000: 768,000,000}}{140}$

$70,744,200$

$40,000-29,388$

$\underline{121,525,904+7,150,000}$

$260,246,050$

$1: 49.44$

\section{Perhitungan} sementara

Hasil Akhir

70.744 .200

$203,760,000$

$\frac{70,744,200}{0.27}$

0.27

$70,744,200$

6,666

10,613

$128,675,904$

$260,246,050$

49.44

2.0225

\section{KESIMPULAN}

Spesifikasi alat pengasapan; tinggi ruang pengasapan $200 \mathrm{~cm}$, diameter alat pengasapan $100 \mathrm{~cm}$, jumlah gantungan alat pengasapan terdiri dari tiga tingkat dan masing masing tingkat terdapat tiga gantungan, rotary pengasapan mempergunakan motor listrik dengan kapasitas 125 watt, dengan putaran $1250 \mathrm{rpm}$, dan untuk memperlambat putaran motor listrik terhadap rotary pengasapan dipergunakan gear box. Kapasiras alat pengasapan $45 \mathrm{~kg}$ dengan lama pengasapan $18 \mathrm{jam}$ pada suhu $4550^{\circ} \mathrm{c}$, dan kebutuhan bahan bakar tempurung kelapa $20 \mathrm{~kg}$.

Analisa parameter kadar air, kadar abu, kadar garam, TPC, E-Coli, Salmonella Staphylococcus, Kapang, terhadap jenis ikan baung (Hemibagrus nemurus), ikan lais (Cryptopterus, Spp) dengan menggunakan alat pengasapan ikan yang direkayasa memenuhi standard SNI ikan asap no 01.2725 1992. Analisa Kadar air terhadap jenis ikan pare asap yang dijual dipasar sebagai pembanding belum memenuhi standard SNI ikan asap.

\section{DAFTAR PUSTAKA}

Badan Standardisasi Nasional, SNI 01 - 2725 1992, SNI lkan Asap.

Bisnis UKM.com. 2007. Teknologi Pengawetan Ikan dengan Cara Pengasapan. http://bisnisukm.com/teknologiipengawetan-ikan-dengan-cara pengasapan.html [diakses pada 20 Nopember 2009]

Dinas Kelautan dan Perikanan Kalimantan Timur. Produksi Ikan Tangkap dan Budidayo Keramba. Kaltim dalam angka 2007

Sirait.J, Guritno.W.M, Mutawakil.A, Mujiyo, Masfut.Z, 2006. Penelition Rekayasa Alat pengering Ikan Dengan Sistim Aliran Air Panas Berbahan Bakar Batubara. Proyek Penelitian dan Pengembangan Industri Propinsi Kalimantan Timur. Departemen Perindustrian Samarinda. 
Kreith.F,1991. Prinsip - Prinsip Perpindohon Panos.

Penerbit Erlangga Jakarta
Wibowo.S, 1996. Industri Pengasapan Ikan. Penerbit Erlangga Jakarta 